\title{
Notes on translation, pronunciation, and archival references
}

The translations from Serbo-Croatian, Slovenian, French, and Italian are mine. The title of documents originally in Cyrillic is always provided in the Latin alphabet. In the text, I use the diacritic signs of the Serbian (Latin) and Croatian alphabet. Serbo-Croatian is completely regular in pronunciation, and there are no silent letters. Eight Serbo-Croatian consonants do not feature in English, and four consonants appear identical but are pronounced differently. They are: $\check{C}$ is $c h$ in 'church'; $c$ is $t$ in 'mixture'; $d z ̌$ is $j$ in 'jam'; $d j$ is $d$ in 'duke'; $r$ is $s h$ in 'shoe'; $\check{z}$ is $s$ in 'treasure'; $l j$ is $l l$ in 'million'; $n j$ is $n$ in 'new'; $c$ is $t s$ in 'Tsar'; $j$ is y in 'yet'; and $h$ and $r$ are always pronounced. Of the remaining consonants, $g$ is always hard (as in 'gag'), and so is $s$ (as in 'sack'). The vowels in Serbo-Croatian sound as follows: $a$ in 'father'; $e$ in 'pet'; $i$ in 'machine'; $o$ in 'hot'; $u$ in 'rule.'

I opted for the US National Archives criteria, which follows the exact opposite sequence of the Archives of Yugoslavia, the Historical Archives of Belgrade, and the Croatian State Archives criteria. ${ }^{1}$ This means I give the references in this order: the type and title of the item, originating office, addressee, date, file number, box and/or files by name and number, series or entry title/name of the collection, record group, and name of the repository. This rule has been respected in all cases, except for the records of the League of Communists of Yugoslavia's (LCY) Central Committee, which have a special identification number (a sequence of Roman and Arabic numbers) that has been inserted between the box number and the entry title. At the time that I accessed the Republican Commission for Cultural Relations with Foreign Countries at the Croatian State Archives, the record group was still unregulated. Therefore, I refer to it by the Archives' temporary references.

\section{Note}

1 L. Benson, Yugoslavia: A Concise History, 2nd edition (Houndmills, Basingstoke; New York: Palgrave Macmillan, 2003), x-xi. 